\title{
ENSINO DE CIÊNCIAS EM PERSPECTIVA EMANCIPATÓRIA
}

\author{
Victor Augusto Bianchetti Rodrigues ${ }^{1}$ \\ Suzani Cassiani ${ }^{2}$
}

\begin{abstract}
Resumo: No Ensino de Ciências ( $E C)$, uma das tendências que tem ganhado destaque é a abordagem temática com enfoque nas relações entre ciência, tecnologia e sociedade (CTS). Alguns autores têm realizado articulações entre os pressupostos do movimento CTS e as ideias de Paulo Freire para conferir maior criticidade ao EC. Nessa articulação, o conhecimento científico surge como instrumento de compreensão e intervenção na realidade dos educandos. Entretanto, é perceptível que muitas contradições sociais, como o racismo e o machismo não têm encontrado solução na ciência. Na verdade, o conhecimento e a prática científica têm contribuído para o aprofundamento dessas contradições. Diante desse contexto, temos como objetivo deste trabalho vislumbrar um EC de fato emancipatório. Pretendemos produzir reflexões que nos auxiliem a responder as seguintes questões: valer-se exclusivamente do conhecimento científico não seria uma resolução de um conflito (ainda dentro da lógica opressora) em vez da superação de uma contradição?; e (ii) quais conhecimentos podem ser utilizados para a superação das contradições típicas de países subdesenvolvidos? Para responder essas questões, fundamentamos nossas reflexões nos estudos decoloniais e nas Epistemologias do Sul. Defendemos que o conhecimento científico não é suficiente para superar as contradições citadas. A Ecologia de Saberes, proposta por Boaventura de Sousa Santos, é uma alternativa para a incorporação de outras formas de conhecimento no EC.
\end{abstract}

Palavras-chave: Ensino de Ciências. Decolonialidade. Epistemologias-do-Sul.

\section{SCIENCE EDUCATION IN AN EMANCIPATORY PERSPECTIVE}

Astract: In Science Education (SE), one of the trends that have gained prominence is the thematic approach focused on the relationships between science, technology and society (STS). Some authors articulate the assumptions of the STS movement and the ideas of Paulo Freire to give a greater criticality to $\mathrm{SE}$. In this articulation, the scientific knowledge arises as an instrument of understanding and intervention in students' reality. However, it is noticeable that many social contradictions, such as racism and chauvinism, have not found a solution in science. In fact, scientific knowledge and scientific practice have contributed to the deepening of these contradictions. Given this context, we have the objective of envisioning an emancipatory SE. We intend to produce reflections

\footnotetext{
${ }_{1}^{1}$ Professor permanente do Instituto Federal do Paraná, Jaguariaíva, Brasil.

2 Professora da Universidade Federal de Santa Catarina, Florianopólis, Brasil
} 
that help us answer the following questions: (i) to rely exclusively on scientific knowledge would not be a resolution of a conflict (still within the oppressive logic) instead of overcoming a contradiction?; and what knowledge can be used to overcome the contradictions typical of underdeveloped countries? To answer these questions, we base our reflections on decolonial studies and Southern Epistemologies. We argue that scientific knowledge is not sufficient to overcome the contradictions cited. The Ecology of Knowledge, proposed by Boaventura de Sousa Santos, is an alternative for the incorporation of other forms of knowledge in SE.

Keywords: Science Education. Decoloniality. Southern Epistemologies.

\section{INTRODUÇÃO}

O movimento Ciência, Tecnologia e Sociedade (CTS) surgiu em países capitalistas centrais (alguns países europeus e Estados Unidos da América) a partir da reflexão sobre os impactos da ciência e da tecnologia na sociedade (AULER; DELIZOICOV, 2001) e teve parte de suas ideias incorporadas por alguns educadores. No Brasil, as ideias do movimento CTS se tornaram mais evidentes a partir da década de 1990, principalmente no campo de pesquisa em Educação Científica e Tecnológica (CHRISPINO et al., 2013).

Alguns autores brasileiros (NASCIMENTO; LINSINGEN, 2006; ROSO; AULER, 2016; SANTOS, 2008; SANTOS, 2011; AULER, 2013; AULER; DELIZOICOV, 2006; STRIEDER, 2008)

têm feito uma articulação entre os pressupostos do movimento CTS e a pedagogia de Paulo Freire. Essa articulação tem sido realizada com o intuito de ressignificar os pressupostos CTS para a educação no contexto brasileiro, de maneira que o conhecimento científico aprendido nas escolas possa ser um instrumento de intervenção na realidade dos educados.

Neste trabalho, reconheço que há avanços quando as articulações entre as ideias freireanas e os pressupostos do movimento CTS são incorporados pelo EC. O conhecimento da educação libertadora pode ser visto como um instrumento de transformação da realidade, ou seja, de proposição ativa de solução para problemas da comunidade ou do mundo do aluno. Entretanto, proponho uma reflexão que vai além disso: qual(is) conhecimento(s) pode(m) ser utilizado(s) para 
a superação das contradições típicas de países subdesenvolvidos? Tradicionalmente, somente a ciência hegemônica é levada em conta no EC. Esse conhecimento é suficiente para a superação de questões tão marcantes do mundo contemporâneo, como a fome, o racismo ou a biodiversidade?

De maneira a aprofundar essa discussão, acredito ser frutífero buscar inspiração nos pressupostos dos estudos decoloniais e das Epistemologias do Sul, para elucidar possíveis contribuições dessas linhas de pensamento para a ressignificação do EC no contexto brasileiro. Ao me fundamentar nesse quadro teórico foi possível vislumbrar características de um EC emancipatório.

\section{O ensino de ciências em perspectiva crítica: até onde avançamos?}

O EC, que até meados da década de 1990 tinha como princípio a formação de cientistas, passou a ter como um de seus objetivos a formação de cidadãos mais críticos, capazes de articular os domínios da ciência, da tecnologia, da sociedade, capacitando-os para as tomadas de decisão requeridas na atualidade (SANTOS, 2007b). O trecho apresentado a seguir foi retirado dos Parâmetros Curriculares Nacionais - PCNs - (BRASIL, 1999; BRASIL, 2002) e evidencia a incorporação dos pressupostos CTS nos documentos oficiais que orientam a prática pedagógica no Brasil.

Seguindo essa tendência e as orientações dos PCNs, o EC a partir da discussão de temas com relevância para a sociedade contemporânea tende a ganhar um lugar de mais destaque dentre as formas de se ensinar ciências no Brasil. Isso pode ser percebido por meio dos vários trabalhos, na forma de relato de experiências, que têm sido realizados na perspectiva CTS, com temáticas como petróleo (SANTA MARIA et al., 2002), meio ambiente (RIBEIRO et al., 2010) , água (QUADROS, 2004), entre outros.

Entretanto, é pertinente perceber que um contexto de subdesenvolvimento, como o brasileiro, tende a originar reinvindicações e reflexões diferentes daquelas de países desenvolvidos. No contexto latino-americano, as articulações CTS não estão restritas a questões ambientais, de desenvolvimento da energia nuclear ou da engenharia genética. É evidente que esses temas são de nosso interesse, uma 
vez que eles têm caráter universal. No entanto, o nosso contexto revela articulações entre CTS que não fazem parte da pauta norte americana ou europeia. Linsingen e Cassiani (2010) alertam para a importância de se considerar as contribuições dos estudos latino-americanos sobre CTS para que sejam desenvolvidas abordagens educacionais socialmente referenciadas.

O campo da Teoria Crítica contribuiu de maneira significativa para 0 processo de identificação dessas temáticas (coerentes com o contexto brasileiro). Em oposição à Teoria Tradicional - a qual compreende a ciência como uma representação neutra da realidade - Horkheimer, Adorno e outros autores da Escola de Frankfurt propuseram a Teoria Crítica. Para esses autores, a ciência é uma produção humana, carregada de dimensões culturais e ideológicas e, portanto, não produz verdades absolutas (CARNAÚBA, 2010).

Nesse sentido, enquanto a Teoria Tradicional aponta para a adaptação à realidade e conformismo, a Teoria Crítica visa compreender a realidade de maneira a perceber as contradições nela presentes (denúncia) para que sejam propostas soluções com caráter emancipatório (anúncio), para a superação das contradições que foram identificadas. Portanto, ao almejar um EC crítico, é importante potencializar o conhecimento sobre práticas de EC que consideram o contexto dos educandos, oportunizando a compreensão da própria realidade (denúncia) e a transformação da mesma (anúncio).

No campo da educação, Paulo Freire é um dos autores que teve grande notoriedade por suas produções em perspectiva Crítica, ou seja, denunciando e anunciando questões do ambiente e da prática educacional. No livro Pedagogia do Oprimido, escrito em 1968, Freire apresenta uma denúncia profunda dos mecanismos pelos quais a sociedade perpetua padrões de opressão. $O$ autor argumenta que a escola, lugar ao qual é creditada a esperança da promoção da transformação social, na verdade, atua como instrumento de conservação da lógica opressora da sociedade e isso se dá por meio da concepção bancária da educação.

Em oposição a essa prática, Paulo Freire propõe a educação libertadora. Nessa perspectiva, os educandos dividem o papel de sujeitos do processo de 
aprendizagem com o educador. Deste ponto surge a ideia de que ninguém educa ninguém, uma vez que a educação libertadora se faz justamente a partir do diálogo do educador com o educando e do educando com o educador.

Segundo Freire (2011), esse diálogo deve ser estabelecido a partir da discussão sobre temas significativos para os estudantes. Nessa abordagem, a comunidade escolar aponta problemas relacionados à realidade concreta dos educandos, por meio do processo de investigação temática. Destarte, os educandos estudam sobre um problema significativo para eles, o que pode fazer com que os mesmos se sintam desafiados a propor uma solução não só no campo intelectual, mas também na ação, de forma a intervir na própria realidade.

Deste ponto pode surgir a interlocução entre movimento CTS e a perspectiva freireana, no contexto do EC. O movimento CTS, conforme apresentado anteriormente, vislumbra a inserção da sociedade nos debates de temas científicos e tecnológicos, de maneira que os cidadãos sejam mais críticos e tenham mais participação nas decisões de cunho tecnocientífico. Em consonância com esses objetivos, Freire propõe a escola como espaço em que pode ser promovida uma educação libertadora, ou seja, uma educação que oportuniza a compreensão sobre as relações entre a sociedade e o mundo, bem como sobre as ferramentas de intervenção nessas relações.

Essa articulação tem sido realizada por alguns autores (citados anteriormente) que se dedicam a estudar sobre o EC com abordagem CTS, com o intuito de ressignificar os pressupostos CTS no contexto brasileiro, como já foi mencionado. Essas articulações têm oportunizado práticas escolares muito mais coerentes e significativas aos educandos. Entretanto, o conhecimento científico hegemônico continua sendo o principal instrumento para a compreensão e intervenção na realidade. Por isso, defendo que devemos avançar ainda mais nas práticas de educação científica, de maneira a incorporar outras formas de conhecimento no ambiente escolar, sem excluir o conhecimento científico.

Esse posicionamento surge do argumento de que para superar uma contradição se faz necessária uma ação inovadora, que altere a lógica de opressão em que vivemos. Se a ação é inovadora, valer-se exclusivamente do 
conhecimento científico não seria uma resolução de um conflito (ainda dentro da lógica opressora) em vez da superação de uma contradição?

A articulação entre os pressupostos freireanos e o movimento CTS no sentido de promover uma reflexão sobre o nosso contexto para que sejam discutidos na escola temas socialmente referenciados. Entretanto, ainda temos que avançar em relação ao tipo de conhecimento que utilizamos para superar as contradições postas no nosso cotidiano. Com intuito de embasar esse posicionamento, utilizo a seguir alguns pressupostos dos estudos decoloniais e das Epistemologias do Sul que têm potencial para ressignificar o EC no contexto brasileiro para que as práticas de educação científica sejam de fato emancipatórias.

\section{Epistemologias do Sul como fundamentos para um ensino de ciências mais do que crítico: Emancipatório}

Assim como Paulo Freire, Boaventura de Sousa Santos também tem sido considerado como um autor de fortes relações com a Teoria Crítica da escola de Frankfurt. Em uma de suas várias aulas magnas disponíveis na internet ${ }^{1}$, o autor português se autodenominou como um sociólogo crítico. Boaventura faz críticas aos modos de atuação que mantêm as estruturas opressoras na sociedade: colonialismo, capitalismo e patriarcado. Em contraposição a essas contradições, Boaventura propõe as Epistemologias do Sul.

As Epistemologias do Sul são um conjunto de práticas cognitivas desenvolvidas a partir das experiências dos grupos sociais que têm sofrido de maneira sistemática as injustiças do capitalismo, do colonialismo e do patriarcado. As localidades em que se encontram esses grupos são denominadas Sul Global e, segundo Boaventura de Sousa Santos (2007), nesses lugares atuam a lógica de Apropriação (dos recursos naturais, dos conhecimentos tradicionais) e de Violência (física, material, cultural e humana). Já as localidades onde estão presentes as elites dominantes são denominadas Norte Global, onde impera o paradigma da Regulação (controle social, ordem) e Emancipação (inclusão, distribuição de riquezas, conquista de direitos). É importante ressaltar que Sul e 
Norte globais não correspondem aos hemisférios geográficos e são separados por uma Linha Abissal, que impossibilita a copresença dos dois hemisférios e silencia o Sul Global.

Historicamente, a ciência moderna e hegemônica foi produzida pelas elites dominantes do Norte Global e está a serviço delas, tornando invisíveis quaisquer outras formas de conhecimento do Sul Global que pudessem colocar em xeque os modos de dominação da modernidade (capitalismo, colonialismo e patriarcado). Por isso, Boaventura defende que essas contradições só podem ser superadas se outras formas de conhecimento forem utilizadas: as Epistemologias do Sul.

Em consonância com a denúncia de Boaventura, Walsh (2009), uma das principais autoras do campo dos estudos decoloniais ${ }^{2}$, afirma que a ciência hegemônica, tradicionalmente ensinada nas escolas, desempenha um papel fundamental na manutenção das estruturas opressoras da sociedade, devido as suas condições de produção e por impossibilitar que os educandos proponham explicações autênticas para a realidade que os cercam. Nesse sentido, se faz necessário o desenvolvimento de novos marcos epistemológicos que rompam com a suposta neutralidade da ciência, de maneira a valorizar saberes socialmente referenciados, historicamente silenciados pela ciência hegemônica (WALSH, 2009).

Assim como Walsh (2009), a autora Azibeiro (2012) destaca a necessidade da emergência - já em curso - de novos paradigmas. Para a autora,

não há um único modelo, uma única verdade absoluta, uma única história em relação à qual todos os povos e situações são olhados e classificados. O múltiplo, o pluriforme diversidade constituem a própria natureza do real (AZIBEIRO, 2012, p.145-146).

Diante do que foi exposto, os pressupostos dos estudos decoloniais, bem como as Epistemologias do Sul, apontam para práticas cognitivas que dão visibilidade a diversas visões de mundo. As articulações entre essa diversidade de conhecimentos podem oportunizar a emancipação do saber, de maneira a valorizar o conhecimento produzido no contexto do Sul Global. A essa articulação entre saberes, Boaventura deu o nome de Ecologia de Saberes. 
Entretanto, para realizar a Ecologia de Saberes é preciso identificar quais conhecimentos foram historicamente silenciados pelo Norte Global. Para isso, Boaventura propõe a Sociologia das Ausências, que consiste justamente em identificar esses conhecimentos. Uma vez identificados, é necessário que se façam visíveis. A esse processo - de dar visibilidade aos conhecimentos silenciados até então - Boaventura deu o nome de Sociologia das Emergências.

Essas duas etapas iniciais para as Epistemologias do Sul podem ser exemplificadas pelo projeto Cinema no Interior ${ }^{3}$. Segundo os próprios idealizadores do projeto, o Cinema no Interior tem por objetivo contribuir com o desenvolvimento sociocultural de comunidades interioranas, utilizando como principal instrumento as ferramentas audiovisuais e a indústria cinematográfica. $O$ projeto realiza pesquisas, oficinas de formação, filmes, livros fotográficos e mostras de cinema mantendo a própria comunidade local como principais pesquisadores, produtores, protagonistas e plateia inicial neste audacioso trabalho de intercâmbio e de valorização da cultura e classe artística interiorana. Em outras palavras, o projeto identifica culturas interioranas (Sociologia das Ausências) e dá visibilidade à produção dessas comunidades por meio das produções audiovisuais (Sociologia das Emergências).

A partir do momento em que conhecemos outras formas de conhecimento, para além da ciência moderna, podemos identificar quais deles podem ser articulados para superar algumas contradições da contemporaneidade. Boaventura defende que o conhecimento não é abstrato e sim uma prática de conhecimento. Nesse sentido, cada conhecimento terá um valor relativo, a depender do tipo de problema que se propõe resolver.

Como exemplo, o racismo. Cientificamente, já foi evidenciado e amplamente divulgado que não há diferenças de raça entre branc@s e negr@s ${ }^{4}$. Entretanto, negr@s continuam subalternizados em relação aos branc@s. Ou seja, o conhecimento científico tem um limite interno na resolução dessa contradição. A própria prática da ciência moderna é racista e machista, uma vez que é majoritariamente feita por homens brancos. Em outras palavras, o conhecimento científico sozinho não dá conta de superar o racismo enraizado na nossa 
sociedade, muito pelo contrário: ele produz e reproduz práticas racistas. Nesse sentido, é necessário que essa forma de conhecimento (a ciência) seja associada a outros conhecimentos (Ecologia de Saberes), como os estudos étnico-raciais que resgatam e valorizam as contribuições d@s negr@s ao longo da história.

Por isso faço a defesa de que o EC seja mais do que crítico, uma vez que nessa perspectiva o conhecimento científico é visto como um instrumento para compreensão e intervenção na sociedade. De fato, esse conhecimento pode contribuir para a emancipação dos sujeitos. Entretanto, é necessário que sejam explicitadas as mazelas que o conhecimento científico causa, bem como é imprescindível o resgate de outros conhecimentos que foram historicamente silenciados pela ciência. Só haverá justiça social, quando houver justiça cognitiva.

\section{Considerações finais}

É evidente que a articulação entre os pressupostos freireanos e o movimento CTS promove avanços ao oportunizar a reflexão sobre o nosso contexto, possibilitando que sejam discutidos na escola temas socialmente referenciados. Entretanto, ainda temos que avançar em relação ao tipo de conhecimento que utilizamos para superar as contradições postas no nosso cotidiano.

Considerando o que foi exposto, as Epistemologias do Sul podem oportunizar a superação de contradições que historicamente são reforçadas pela ciência moderna hegemônica. É importante ressaltar que o que está em proposta não é o silenciamento desse conhecimento, mas o seu uso em perspectiva contrahegemônica. Utilizar a ciência moderna em perspectiva contra-hegemônica pressupõe reconhecer as formas pelas quais ela propicia a manutenção das estruturas opressoras da sociedade e, mais do que isso, perceber as limitações dessa visão de mundo para a resolução dos problemas que estão postos no Sul Global (oriundos do capitalismo, colonialismo e patriarcado, por meio da lógica da Apropriação e Violência).

Nesse sentido, argumento que outros conhecimentos, para além da ciência hegemônica, devem se fazer presente no EC. Entendo que esse é um grande 


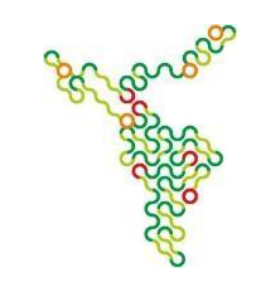

desafio e que experiências em espaços de resistência, como comunidades indígenas e movimentos sociais, podem revelar características de grande valor para uma educação científica em perspectiva emancipatória. Tais experiências podem elucidar orientações para a formação de professores de ciências e para o desenvolvimento de práticas que considerem as reflexões e os diversos saberes pertinentes ao contexto de um país desigual e subdesenvolvido. Nesse sentido, o EC apoiado nas Epistemologias do Sul e nos estudos decoloniais pode ser um instrumento de emancipação e modificação das estruturas opressoras da sociedade.

\section{Referências}

AULER, D.; DELIZOICOV, D. Alfabetização científico-tecnológica para quê?. Ensaio Pesquisa em Educação em Ciências, v. 3, n. 2, p. 122-134, 2001.

AULER, D; DELIZOICOV, D. Educação CTS: articulação entre pressupostos do educador Paulo Freire e referenciais ligados ao movimento CTS. Seminário Ibérico CTS no ensino das ciências: las relaciones CTS en la Educación Científica, v. 4, p. 1-7, 2006.

AULER, D. Articulação entre pressupostos do educador Paulo Freire e do movimento CTS: novos caminhos para a educação em ciências. Revista Contexto \& Educação, v. 22, n. 77, p. 167- 188, 2013.

AZIBEIRO, N. E. Desconstrução de subalternidades e mudanças paradigmáticas. Revista Pedagógica, v. 14, n. 28, p. 143-176, 2012.

BRASIL. Ministério da Educação (MEC), Secretaria de Educação Média e Tecnológica (SEMTEC).

Parâmetros Nacionais para o Ensino Médio. Brasília: MEC/SEMTEC, 1999.

Ministério da Educação (MEC), Secretaria de Educação Média e Tecnológica (SEMTEC). PCN + Ensino Médio: orientações educacionais complementares aos Parâmetros Curriculares Nacionais - Ciências da Natureza, Matemática e suas Tecnologias. Brasília: MEC/SEMTEC, 2002.

CARNAÚBA, Maria Érbia Cássia. Sobre a distinção entre teoria tradicional e teoria crítica em Max Horkheimer. Kínesis-Revista de Estudos dos PósGraduandos em Filosofia, v. 2, n. 03, 2014.

CHRISPINO, A. et al. A área CTS no Brasil vista como rede social: onde aprendemos?. Ciência e Educação, Bauru, v. 19, n. 2, p. 455-479, 2013. 


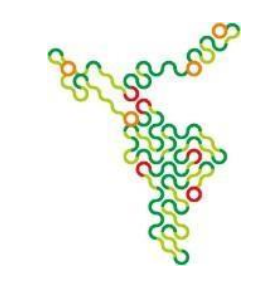

FREIRE, P. Pedagogia do oprimido. Rio de Janeiro: Paz e Terra, v. 17, 2011.

LINSINGEN, I.; CASSIANI, S. Educação CTS em perspectiva discursiva: contribuições dos estudos sociais da ciência e da tecnologia. Redes, v. 16, n. 31, p. 163-182, 2010.

NASCIMENTO, T. G.; LINSINGEN, I. von. Articulações entre o enfoque CTS e a pedagogia de Paulo Freire como base para o ensino de Ciências. Convergência, v.13, n.42, p.95-116, 2006

QUADROS, A. L. A água como tema gerador do conhecimento químico. Química Nova na Escola, n. 20, p. 26-31, 2004.

RIBEIRO, E. M. F.; MAIA, J. O.; WARTHA, E. J. As Questões Ambientais e a Química dos Sabões e Detergentes. Química Nova na Escola, v. 32, n. 3, 2010. ROSO, C. C.; AULER, D. A participação na construção do currículo: Práticas educativas vinculadas ao movimento CTS. Ciência \& Educação (Bauru), v. 22, n. 2, p.371-389, 2016.

SANTA MARIA, L.C.; AMORIM, M.C.V; AGUIAR, M.R.P; SANTOS, Z.A.M; CASTRO,

P.S.C.B.G; BALTHAZAR, R.G. Petróleo: um tema para o Ensino de Química. Química Nova na Escola, n.15, p 19-23, 2002.

SANTOS, B. de S. Para além do pensamento abissal: das linhas globais a uma ecologia de saberes. Novos estudos-CEBRAP, n. 79, p. 71-94, 2007 a.

SANTOS, W. L. P. Contextualização no ensino de Ciências por meio de temas CTS em uma perspectiva crítica. Ciência \& Ensino, v. 1, 2007b.

SANTOS, W. L. P. Educação científica humanística em uma perspectiva freireana: resgatando a função do ensino de CTS. Alexandria: Revista de Educação em Ciência e Tecnologia, v. 1, n. 1, p. 109-131, 2008.

SANTOS, W. L. P. Significados da educação científica com enfoque CTS. In: SANTOS, W. L. P.; AULER, D. CTS e educação científica: desafios, tendências e resultados de pesquisa. Brasília: Editora Universidade de Brasília, p. 21- 47, 2011.

STRIEDER, R. B. Abordagem CTS e ensino médio: espaços de articulação. Tese de Doutorado. Universidade de São Paulo. São Paulo, 2008.

WALSH, C. Interculturalidad crítica y pedagogía de-colonial: apuestas (des) de el in-surgir, re- existir y re-vivir. UMSA Revista (entre palabras), v. 3, 2009. 